\title{
Induced lipid peroxidation in ram sperm: semen profile, DNA fragmentation and antioxidant status
}

\author{
Thais Rose dos Santos Hamilton ${ }^{1}$, Letícia Signori de Castro ${ }^{1}$, Juliana de Carvalho Delgado ${ }^{1}$, \\ Patrícia Monken de Assis ${ }^{1}$, Adriano Felipe Perez Siqueira ${ }^{1}$, Camilla Mota Mendes ${ }^{1}$, \\ Marcelo Demarchi Goissis ${ }^{1}$, Teresa Muiño-Blanco ${ }^{2}$, José Álvaro Cebrián-Pérez ${ }^{2}$, Marcílio Nichi ${ }^{1}$, \\ José Antonio Visintin ${ }^{1}$ and Mayra Elena Ortiz D'Ávila Assumpção ${ }^{1}$
}

${ }^{1}$ Department of Animal Reproduction, School of Veterinary Medicine and Animal Science, University of Sao Paulo. Avenida Prof. Dr. Orlando Marques de Paiva, 87, 05508 270, Cidade Universitária, Sao Paulo, Brazil and ${ }^{2}$ Grupo de Biología y Fisiología de la Reproducción, Facultad de Veterinaria, Instituto de Investigación de Ciencias Ambientales de Aragón (IUCA), Department of Biochemistry and Molecular and Cell Biology, University of Zaragoza,

Miguel Servet, 177, 50013 Zaragoza, Spain

Correspondence should be addressed to ME O D'Ávila Assumpção; Email: meoaa@usp.br

\begin{abstract}
Action of reactive oxygen species, protamination failures and apoptosis are considered the most important etiologies of sperm DNA fragmentation. This study evaluated the effects of induced lipid peroxidation susceptibility on native semen profile and identified the mechanisms involved in sperm DNA fragmentation and testicular antioxidant defense on Santa Ines ram sperm samples. Semen was collected from 12 adult rams (Ovis aries) performed weekly over a 9-week period. Sperm analysis (motility, mass motility, abnormalities, membrane and acrosome status, mitochondrial potential, DNA fragmentation, lipid peroxidation and intracellular free radicals production); protamine deficiency; PRM1, TNP1 and TNP2 gene expression; and determination of glutathione peroxidase (GPx), glutathione reductase, catalase (CAT) and superoxide dismutase activity and immunodetection in seminal plasma were performed. Samples were distributed into four groups according to the sperm susceptibility to lipid peroxidation after induction with ascorbate and ferrous sulfate (low, medium, high and very high). The results were analyzed by GLM test and post hoc least significant difference. We observed an increase in native GPx activity and CAT immunodetection in groups with high susceptibility to induced lipid peroxidation. We also found an increase in total sperm defects, acrosome and membrane damages in the group with the highest susceptibility to induced lipid peroxidation. Additionally, the low mitochondrial membrane potential, susceptible to chromatin fragmentation and the PRM1 mRNA were increased in the group showing higher susceptibility to lipid peroxidation. Ram sperm susceptibility to lipid peroxidation may compromise sperm quality and interfere with the oxidative homeostasis by oxidative stress, which may be the main cause of chromatin damage in ram sperm.

Reproduction (2016) 151 379-390
\end{abstract}

\section{Introduction}

Sperm, like all aerobic cells, lives in a constant oxygen paradox. Oxygen is essential for life; however, metabolites of aerobic respiration can be extremely detrimental. During the process of spermatogenesis, reactive oxygen species (ROS) are generated by sperm metabolism. Accumulation of ROS can cause an imbalance in relation to the activity of antioxidant molecules, leading to oxidative stress (OS), which is extremely damaging to all sperm components. Maintaining a balance between generation neutralization of ROS occurs due to the antioxidant capacity of sperm and seminal plasma. The enzymatic and non-enzymatic antioxidants in seminal plasma protect plasma membrane from peroxidation (Lenzi et al. 2000, Kankofer et al. 2005).

OS has been reported, directly or indirectly, as the main cause of male infertility (Aitken \& Clarkson 1987, Aitken \& Barker 2002, Agarwal et al. 2003, 2008, 2014). A balanced antioxidant environment is required for fertility, as ROS are necessary for fertilization, acrosome reaction, sperm hyperactivation, sperm motility and sperm capacitation (Aitken \& Barker 2002). Enzymes such as superoxide dismutase (SOD) and catalase (CAT), as well as agents capable of blocking oxidative reactions, carry antioxidant action in the seminal environment. Reduced sperm cytoplasm limits the intracellular 
antioxidant content. As OS is the result of an imbalance between ROS and existing antioxidants (Halliwell \& Gutteridge 2007), this imbalance is consistently associated with sperm abnormalities, resulting in infertility (Agarwal et al. 2014). Increased levels of ROS have been correlated with decreased sperm motility and DNA damage (Gomez et al. 1998). OS represents a source of damage, as spermatozoa are extremely susceptible to ROS. Sperm membranes are rich in polyunsaturated fatty acids, which are easily oxidized (Parks \& Hammerstedt 1985).

Ram sperm presents an excessively high proportion of polyunsaturated/saturated fatty acids and low proportion of cholesterol/phospholipids in the plasma membrane when compared to other species (Watson 1981, White 1993, Holt 2000). This particular condition makes ram sperm membrane prone to peroxidative damage by ROS, causing loss of membrane and acrosome integrity (Alvarez \& Storey 1992). One of the most striking deleterious effects of OS on sperm is chromatin damage (Sakkas \& Alvarez 2010), which is linked to disturbances in resulting embryos (Aitken \& Krausz 2001, Fatehi et al. 2006, Makker et al. 2009), fetuses, newborns and even next generations (Virro et al. 2004) alterations. Sperm DNA fragmentation is the ultimate effect of OS in the chromatin, and it has been related to embryo development failure (Virro et al. 2004) and infertility in adults (Tesarik et al. 2002). However, it is important to note that sperm with fragmented chromatin can fertilize the oocyte (Evenson \& Wixon 2006). Small extension or incidence of sperm DNA damage can be repaired by the oocyte after fertilization or during embryo development. However, if the damage is extensive, even if fertilization takes place, apoptosis and embryonic fragmentation should occur (Ahmadi \& Ng 1999, Tamburrino et al. 2012).

There are six main causes of damage to nuclear and mitochondrial chromatin in the sperm: i) apoptosis during spermatogenesis; ii) problems in the chromatin remodeling during spermatogenesis (protamination); iii) action of ROS, especially hydroxyl radical and nitric oxide, during transport of sperm through the seminiferous tubules and epididymis; iv) fragmentation induced by caspases and endonucleases; v) radiation and chemotherapy; and vi) environmental toxicants (Sakkas \& Alvarez 2010). Testicular and epididymal OS seem to be the most important cause among these mechanisms of sperm DNA fragmentation (Agarwal et al. 2003). Oxidative damages in sperm DNA include changes and deletions in nitrogenous bases, DNA cross-links, chromosomal rearrangements: DNA strands breaks, mutations and polymorphisms. In addition, studies indicate that $\mathrm{OS}$ is also involved in impaired sperm DNA packaging (Hammadeh et al. 2010). Notwithstanding, there is still controversy in regard to the causes or effects of defective sperm DNA packaging, DNA fragmentation and OS.
One of the most widely used techniques to assess semen oxidative status is the measurement of lipid peroxidation by-products after incubation with an OS promoter system, thus evaluating sperm susceptibility to an oxidative environment (Aitken et al. 1993, Bansal \& Bilaspuri 2008, Simões et al. 2013, Mojica-Villegas et al. 2014). In rams, there is little data about the OS effect on sperm DNA packaging and fragmentation, especially under physiological conditions. We then hypothesized that oxidative status regulates/impacts the sperm characteristics and chromatin damage in ram sperm. Thus, the goal of this study was to evaluate the effects of oxidative status on ram conventional semen profile and identify the mechanisms involved in sperm DNA fragmentation and testicular antioxidant defense. Conventional and functional sperm tests such as sperm viability; DNA fragmentation; protamine deficiency; PRM1, TNP1 and TNP2 gene expression; and determination of antioxidant enzymes activity and quantity in seminal plasma were performed in semen samples that were distributed into four groups according to the sperm susceptibility to OS.

\section{Materials and methods}

Unless otherwise indicated, all chemicals were obtained from Sigma Chemicals.

Animals belonged to the Department of Animal Reproduction of the School of Veterinary Medicine and Animal Science from the University of Sao Paulo. Animals were submitted to uniform nutritional conditions. The Bioethics Committee of the School of veterinary medicine and Animal Sciences, University of Sao Paulo, approved the experiments (protocol \# 2445-20).

\section{Experimental design}

All experiments were performed using fresh ram semen, which was collected using an artificial vagina. Collections were performed weekly over a 9-week period from 12 adult (8-month old) Santa Ines rams (Ovis aries). Each sample was retrospectively divided into four groups according to the resistance of sperm to OS, as evaluated by the measurement of the thiobarbituric acid reactive substances (TBARS) after incubation with a ROS generating system (Table S1, see section on supplementary data given at the end of this article). The median and quartiles were calculated and used to determine the limit values for each group. Group 1 included the minimum value to the bottom quartile (low, $n=27$ ); group 2 included the lower quartile to the median (average, $n=27$ ); group 3 included the median to the upper quartile (high, $n=27$ ); and group 4 included the upper quartile to the maximum (highest, $n=27$ ) (Fig. 1). All samples were used in all experiments.

\section{Sperm TBARS}

The TBARS reaction evaluates the levels of malondialdehyde, a product of lipid peroxidation. This technique is based on methodology previously described by Ohkawa et al. (1979), in which two thiobarbituric acid molecules reacted with one 


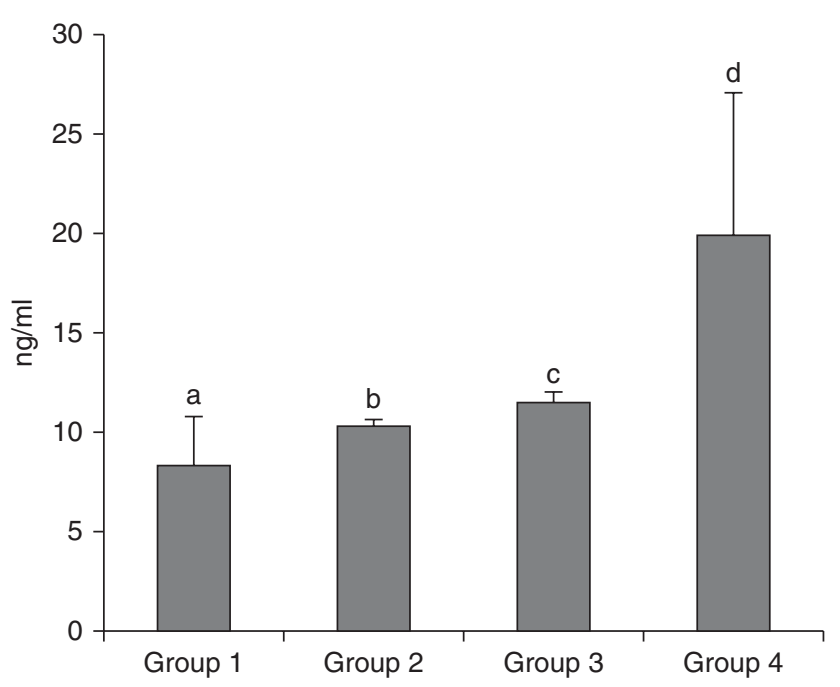

Figure 1 TBARS in ram sperm in different TBARS groups (groups 1, 2, 3 and 4 ). The results are presented as means \pm s.D. Different superscript letters in each bar represent significant differences $(P<0.05)$.

molecule of malondialdehyde, producing a pink color complex, which was measured spectrophotometrically at $532 \mathrm{~nm}$. This reaction occurs between 90 and $100^{\circ} \mathrm{C}$ at an acidic $\mathrm{pH}$. In brief, one million sperm (diluted in $200 \mu \mathrm{l}$ PBS) were incubated with $4 \mathrm{mM}$ of ferrous sulfate $(50 \mu \mathrm{l})$ and $20 \mathrm{mM}$ ascorbate $(50 \mu \mathrm{l})$ at $37^{\circ} \mathrm{C}$ for $1.5 \mathrm{~h}$, as described by Simões et al. (2013). Immediately after ROS induction, $600 \mu \mathrm{l}$ of $10 \%(\mathrm{v}: \mathrm{v})$ trichloroacetic acids were added to the mixture $(2: 1)$ in order to precipitate proteins and cellular debris. Samples were centrifuged $(16000 \mathrm{~g}$, for $10 \mathrm{~min})$ and the supernatant recovered $(500 \mu \mathrm{l})$ and stored $\left(-20^{\circ} \mathrm{C}\right)$. Samples were thawed and incubated with $500 \mu \mathrm{l}$ thiobarbituric acid $1 \%$ solution (in $\mathrm{NaOH} 0.05 \mathrm{M}$ ) for 10 min at 90-100 ${ }^{\circ} \mathrm{C}$. Reaction was stopped by placing samples on ice. Levels of TBARS were assessed using a spectrophotometer with $532 \mathrm{~nm}$ wavelengths. Results were compared to a standard curve previously prepared with malondialdehyde. Malondialdehyde is the major substance that reacts with thiobarbituric acid, and the TBARS concentration was determined using the value of $1.56 \times 10^{5} \mathrm{M} / \mathrm{ml}$ as the malondialdehyde molar extinction coefficient. Lipid peroxidation in sperm was expressed in nanograms of TBARS $/ 10^{6}$ sperm.

\section{Flow cytometry analysis}

Flow cytometry analysis of sperm samples was performed using Guava EasyCyte Mini System (Guava Technologies, Hayward, CA, USA). This equipment contains a blue laser, which operates at $488 \mathrm{~nm}$ and emits a $20 \mathrm{~mW}$ visible laser radiation. A total of 10000 events per sample were analyzed, and data corresponding to yellow (PM1 photodetector, $583 \mathrm{~nm}$ ), red (PM2 photodetector, $680 \mathrm{~nm}$ ) and green fluorescent signals (PM3 photodetector, $525 \mathrm{~nm}$ ) were recorded after a logarithmic amplification. For analysis, alien particles such as cell doublets and main debris were excluded using PM2/FSC (forward scatter) despite the relatively low incidence of such particles in fresh semen (Hossain et al. 2011). All data were analyzed by using Flowlo version 8.7 Software (Ashland, OR, USA).

\section{Oxidative status}

\section{Seminal plasma TBARS}

For the determination of TBARS in seminal plasma, aliquots of $300 \mu \mathrm{l}$ of fresh semen associated with $600 \mu \mathrm{l}$ of $10 \%$ trichloroacetic acid solution were centrifuged at $5{ }^{\circ} \mathrm{C}, 16000 \mathrm{~g}$ for $10 \mathrm{~min}$ to precipitate the proteins. Aliquots of $700 \mu \mathrm{l}$ from the supernatant were frozen at $-20^{\circ} \mathrm{C}$ for subsequent analysis, which was performed as previously described.

\section{Sperm free radical quantification}

Sperm OS was assessed by the fluorescent probe dichlorofluorescein $\left(2^{\prime}, 7^{\prime}\right.$ dichlorofluorescein diacetate, DCF). DCF emits fluorescence when in contact with free radicals (Gomes et al. 2005, Mahfouz et al. 2009, Kim et al. 2010). Evaluations were performed by flow cytometry. In brief, 4000 spermatozoa were resuspended in $1 \mu \mathrm{l}$ of Tyrode's Albumin Lactate Pyruvate (TALP) medium and incubated with $3.5 \mu \mathrm{l}$ of $1 \mathrm{mM}$ fluorescent probe DCF. Propidium iodide (PI; $0.5 \mathrm{mg} / \mathrm{ml}$, $0.5 \mu \mathrm{l}, 5 \mathrm{~min}$ ) was added to identify and exclude cells with damaged membrane, as this condition does not allow proper function of DCF stain. After a 5-min incubation period, flow cytometer analysis was performed as described above using the $525 \mathrm{~nm}$ detector (green fluorescence).

\section{Seminal plasma enzymatic activity}

Seminal plasma was obtained by centrifuging $500 \mu \mathrm{l}$ of fresh semen at $5{ }^{\circ} \mathrm{C}$ for $10 \mathrm{~min}$ at $660 \mathrm{~g}$. Seminal plasma was then stored at $-20^{\circ} \mathrm{C}$ so that all analyses could be carried out simultaneously. Measurements were performed based on the rate of substrate consumption in reactions catalyzed by each antioxidant enzyme in a given time interval using a spectrophotometer (Evolution 300 UV-Vis, Thermo Scientific, Waltham, MA, USA). Activities of SOD, glutathione peroxidase (GPx) and glutathione reductase (GRD) were determined, as described previously (Marti et al. 2003). In addition, CAT activity was determined by evaluating the consumption of hydrogen peroxide for $3 \mathrm{~min}$ at $242 \mathrm{~nm}$, and the $18.6 \times 10^{3} / \mathrm{cm}$ per $\mathrm{M}$ molar extinction coefficient was used.

\section{SDS-PAGE and western blotting}

We quantified total protein concentration (Protein Assay, Bio-Rad) in seminal plasma by Bradford method (Bradford 1976). Then, $20 \mathrm{mg}$ protein were mixed with $5 \mu \mathrm{l}$ loading buffer $(0.045 \mathrm{M}$ Tris/ $\mathrm{HCl}, 0.8 \mathrm{mM}$ EDTA, $3 \%$ SDS $10 \%$ glycerol, 5\% $\beta$-mercaptoethanol and $0.004 \%$ bromophenol blue) and were loaded into wells. Proteins were separated by dimension on $12 \%$ polyacrylamide gel $(\mathrm{v} / \mathrm{v})$ by standard SDSPAGE using a Mini-PROTEAN III System (Bio-Rad). A mixture of pre-stained protein standards, with molecular weights ranging from 10 to $250 \mathrm{kDa}$ (Bio-Rad), was used as marker. Electrophoresis was performed for $90 \mathrm{~min}$ at $130 \mathrm{~V}$ at $4{ }^{\circ} \mathrm{C}$. Subsequently, the proteins were blotted onto PVDF membranes using the Trans-Blot Turbo for $10 \mathrm{~min}$ at 2.5A-25V (Bio-Rad). After air drying the membrane, blocking was performed for non-specific sites with 5\% BSA in PBS for $0200 \mathrm{~h}$. Membranes were incubated overnight with primary antibodies: anti-CAT 
(SC 50508, H-300, Santa Cruz Biotechnology), anti-SOD (SOD-3, SC 67088, H-90, Santa Cruz Biotechnology), antiGPx (GPx-5, SC 50498, H-45, Santa Cruz Biotechnology) and anti-GRD (anti-GRD antibody ab84963, Abcam, Cambridge, $\mathrm{FI}$, UK) were diluted in 1/1000 PBS/Tween with 1\% BSA. After a series of three washes every $5 \mathrm{~min}$, membranes were incubated with secondary donkey anti-rabbit antibody (Li-COR Biotechnology, Bad Homburg, Germany, 1/15 000 PBS/Tween with $1 \% \mathrm{BSA}$ ) for $75 \mathrm{~min}$ at room temperature and were protected from light. Quantification of signal intensities and areas of bands were performed by scanning the membranes using Odyssey CLX (Li-Cor Biotechnology). Results were expressed considering the relation between signal (pixel) and band area.

\section{Immediate and morphological sperm evaluations}

After collection, semen was kept in water bath at $37-38^{\circ} \mathrm{C}$. The following evaluations were immediately performed: seminal volume $(\mathrm{ml})$, motility $(\%)$ and mass motility (0-5). Sperm concentration count was performed using a Neubauer chamber. Sperm morphological abnormalities were assessed in $10 \mu \mathrm{l}$ fresh semen fixed in $1 \mathrm{ml}$ buffered formalin (PBS; Gibco and Life Technologies, with $2 \%$ of formalin $37 \%$ ) and were evaluated in a phase contrast microscope at $1000 \times$ magnification under oil. Sperm abnormalities were quantified and classified into major and minor defects, and the sum of defects was considered as total defects (Blom 1973). A total of 200 cells per sample were evaluated.

\section{Plasma membrane and acrosome integrity and mitochondrial membrane potential}

Plasma membrane and acrosome integrities were evaluated by $\mathrm{PI}$ and FITC Pisum sativum agglutinin (FITC-PSA) respectively. This association of fluorescent probes divides sperm populations into four groups: intact membrane and intact acrosome (IMIA), intact membrane and damaged acrosome (IMDA), damaged membrane and intact acrosome (DMIA) and damaged membrane and damaged acrosome (DMDA). The procedure was performed with 200000 cells diluted in SP-TALP

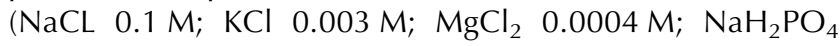
$0.0003 \mathrm{M} ; \mathrm{NaHCO}_{3} 0.025 \mathrm{M}$; $\mathrm{CaCl}_{2} \mathrm{H}_{2} \mathrm{O} 0.003 \mathrm{M}$; acido láctico syrup 0.3\% v/v; HEPES 001 M; pH 7.4; Osm 295-300), stained with $0.5 \mathrm{mg} / \mathrm{ml} \mathrm{PI}$ in $\mathrm{NaCl} 0.9 \%$ and $100 \mu \mathrm{g} / \mathrm{ml}$ FITC-PSA (FITC-PSA L-0770) in a sodium azide solution at $10 \%$ in DPBS. Samples were analyzed by flow cytometry after $10 \mathrm{~min}$, excited at $488 \mathrm{~nm}$ and detected at 630-650 nm (PI) and 515-530 nm (FITC). Mitochondrial membrane potential was evaluated by JC-1 probe $\left(5,5^{\prime}, 6,6^{\prime}\right.$-tetrachloro-1, $1^{\prime}, 3,3^{\prime}$-tetraethyl-benzimidazolylcarbocyanine chloride, Invitrogen). This probe emits green fluorescent light from cells with low mitochondrial potential (LMP) and medium mitochondrial potential (MMP) or red-orange fluorescent from high mitochondrial potential (HMP). The procedure was performed with 200000 cells diluted in SP-TALP and stained with $76.5 \mu \mathrm{M} \mathrm{JC}-1$ in DMSO. Samples were analyzed by flow cytometry after $10 \mathrm{~min}$, excited at $488 \mathrm{~nm}$ and detected at $590 \mathrm{~nm}$.

\section{Protamine assessment in sperm chromatin}

Protamine deficiency

Chromomycin A3 (CMA3) fluorochrome was used to investigate protamine deficiency in ram sperm cells, as described before (Simões et al. 2009) substituting microscopy analysis with flow cytometry. About 30 million spermatozoa from each ejaculate were washed in PBS without calcium (Ca) and magnesium (Mg), by centrifugation at $9000 \mathrm{~g}$ for 60 s. Samples were then fixed in Carnoy's solution (three parts methanol: one part of acetic acid) at $4{ }^{\circ} \mathrm{C}$. After $10 \mathrm{~min}$, an additional wash was performed with PBS without $\mathrm{Ca}$ and $\mathrm{Mg}$. The pellet was stained with $0.25 \mathrm{mg} / \mathrm{ml} \mathrm{CMA3}$ solution for $20 \mathrm{~min}$ at room temperature and in the dark. Samples were then washed with PBS without Ca and Mg. The pellet was then resuspended in PBS and samples submitted to flow cytometry analysis using the $583 \mathrm{~nm}$ detector (PM1) corresponding to yellow. Decondensed sperm nucleus and extraction of protamines was used as a control, obtaining a deprotaminated cell pattern according to Simões et al. (2009).

\section{Gene expression of PRM1, TNP1 and TNP2 in ram sperm}

One sample from every ejaculate, from each animal, was used for RNA isolation. After semen collection, samples with $10^{6}$ spermatozoa were washed in PBS. RNAlater solution (Life Technologies) was added to the pellet to stabilize RNA. Samples were kept in liquid nitrogen until RNA isolation. Spermatozoa membrane was disrupted (snap freezing) and then the RNA isolation was carried using Trizol, according to manufacturer's instructions (Life Technologies). Traces of DNA were removed by DNAse treatment using the Pure Link DNAse, (Invitrogen). Isolated RNA was evaluated using NanoDrop ND-1-Spectrophotometer (Thermo Scientific), and 280/260 values between 1.9 and 2.1 were considered adequate. CDNA was synthesized using Superscript VILO cDNA Synthesis kit following manufacturer's instructions (Life Technologies). Quantification of cDNA was performed using Qubit dsDNA BR and Qubit 2.0 Fluorometer (Life Technologies), and cDNA samples were diluted to $2.5 \mu \mathrm{g} / \mathrm{ml}$. Primers for PRM1 (PRM1 - forward primer: ACAGTAACCGCACAGTAGCA, reverse primer: GTGGCATTGTTCGTCAGCAG), TNP1 (TNP1 - forward primer: GCTGTGATGATGCCAATCGC, reverse primer: GTCCCCСТTCTGTTCGGTTG) and TNP2 (TNP2 - forward primer: GTCCCCCTTCTGTTCGGTTG, reverse primer: TCAGTTGTACTTCCGTCCTGAG) were designed using the online software Primer-BLAST (http://www. ncbi.nlm.nih.gov/tools/primer-blast) based on the sequences of the respective $O$. aries transcripts (NM001163050.0 PRM1, XM_004004917.1 predicted TNP1 and XM_004020771.1 predicted TNP2). PCR was first carried out to verify the presence of these transcripts in spermatozoa. Then, absolute qPCR was performed to calculate the number of copies of target genes in each sample. In order to calculate these values, each target gene was amplified by PCR, sequenced and cloned into pGEM T Easy Vector System I plasmid vector (Promega). A seven-point standard curve with tenfold serial dilutions, known concentration and known copy number, was used in each PCR assay. qPCR was performed in triplicates using SYBR GreenER qPCR Supermix Universal kit (Life Technologies) in a Mastercycler ep 
realplex Thermal Cycler (Eppendorf AG, Hamburg, Germany). PCR consisted of 40 amplification cycles of $95^{\circ} \mathrm{C}$ for $15 \mathrm{~s}$ and $60{ }^{\circ} \mathrm{C}$ for $60 \mathrm{~s}$. Copy number was calculated based on the standard curve described above considering the concentration of cloned products, product size and length of the plasmid vector (www.thermoscientificbio.com/webtools/copynumber).

\section{Sperm DNA fragmentation evaluation}

Assessment of sperm DNA integrity

Sperm DNA fragmentation was qualitatively evaluated by flow cytometry after acid-induced denaturation using the metachromatic fluorophore acridine orange, as described previously (Simões et al. 2013). Green color designates the presence of dsDNA, while red designates the presence of ssDNA, which indicates denaturation of the chromatin structure.

\section{Assessment of DNA integrity by a modified alkaline comet assay}

The modified alkaline comet assay was used to assess sperm DNA integrity, as described previously (Donnely et al. 2000). The image display was obtained by epifluorescence microscope, Olympus IX with 515-560 nm excitation filter and $600 \mathrm{~nm}$ barrier filter, equipped with an Olympus Q-Color camera (Olympus, Tokyo, Japan). The images of 200 cells were randomly selected and analyzed by visual grading in degrees from I to IV according to the intensity of DNA damage. Grade I consisted of sperm with a surrounding halo and stained nuclei, without an evident comet tail, indicating little fragmentation. Grade II consisted of sperm with comet tail formation and a pale core light, indicating DNA damage. Grade III consisted of sperm cells with fully formed comet tails, yet with the core partially stained, indicating obvious DNA damage, and Grade IV consisted of sperm with fully formed comet tail and with a completely stained core, indicating intense DNA fragmentation.

\section{Statistical analysis}

Statistical analysis was performed using the software Statistical Analysis System (SAS Institute, Cary, NC, USA). Data were tested for normality of residues and homogeneity of variances. Outliers were identified and discarded accordingly in each dependent variable. Variables that did not comply with these statistical premises were subjected to transformations. We used the GLM procedure of the software considering the effect on lipid peroxidation, and comparison of means was made using the least significant difference procedure. Spearman correlations analysis was performed to verify the correlation between variables analyzed, using the CORR procedure. All statistical analyses were calculated with a significance level of $5 \%$.

\section{Results}

\section{Relationship between dependent variables}

The correlation analysis revealed that the quantification of sperm TBARS correlated significantly with the variables related to antioxidant status (positively with the activity of GPx and immunodetection of CAT, and negatively with the activity of GRD), semen profile (negatively with sperm concentration and positively with percentage of IMIA, total defects and major defects) and DNA fragmentation (positively with percentage of cells stained with acridine orange and number of PRM1 mRNA copies and negatively with number of PRM2 mRNA copies) (Table S2, S3 and S4, see section on supplementary data given at the end of this article).

\section{OS and antioxidant enzyme}

As OS is determined by an imbalance of ROS and antioxidants, the activity and levels of antioxidant enzymes were assessed to investigate a possible recovery mechanism from a stressed environment. There was no effect of induced lipid peroxidation susceptibility on native sperm-free radical quantification by the fluorescent probe dichlorofluorescein $(9.11 \pm 1.70,9.09 \pm$ $1.95 \%, 6.06 \pm 1.60 \%, 9.58 \pm 2.27 \%$ for groups $1,2,3$ and 4 respectively). The determination of native TBARS in ram seminal plasma did not differ among groups
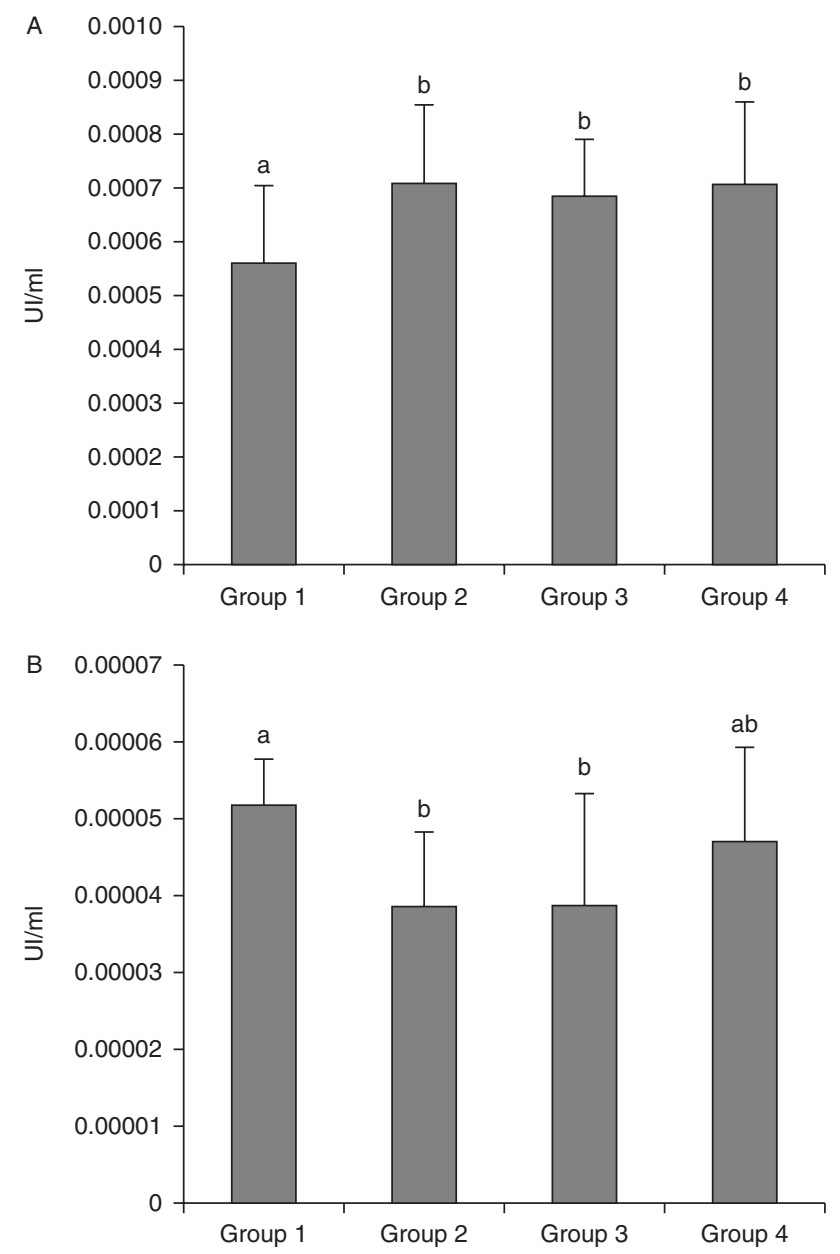

Figure 2 Enzymatic activity of GPx (A) and GRD (B) in ram seminal plasma in different TBARS groups (groups 1,2,3 and 4). The results are presented as means \pm s.D. Different superscript letters in each bar represent significant differences $(P<0.05)$. 
$(246.08 \pm 15.8,215.73 \pm 14.7,261.88 \pm 13.7,217.12 \pm$ $18.9 \mathrm{ng} / \mathrm{ml}$ for groups $1,2,3$ and 4 respectively). Native enzymatic activities of GPx, GRD, SOD and CAT were measured by substrate consumption. There was an increase in native GPx activity in groups with higher susceptibility to lipid peroxidation $(0.000709 \pm 0.00004$, $0.000687 \pm 0.00003,0.000709 \pm 0.00006 \mathrm{IU} / \mathrm{ml}$ for groups 2, 3 and 4 respectively; Fig. 2A) compared to the group with lower susceptibility to induced lipid peroxidation $(0.000561 \pm 0.00004 \mathrm{IU} / \mathrm{ml}$ for group 1 ; Fig. 2A). However, native enzymatic activity of GRD was decreased in groups with higher susceptibility to induced lipid peroxidation $(0.000039 \pm 0.000003$, $0.000039 \pm 0.0000043, \quad 0.0000475 \pm 0.0000053 \mathrm{lU} / \mathrm{ml}$ for groups 2, 3 and 4 respectively; Fig. 2B) compared to the group with the lowest susceptibility to lipid peroxidation $(0.000052 \pm 0.000002 \mathrm{IU} / \mathrm{ml}$ for group 1; Fig. 2B). No differences in enzymatic activity of native SOD activity $(0.120 \pm 0.004,0.128 \pm 0.0049,0.120 \pm$ $0.0074,0.111 \pm 0.009 \mathrm{IU} / \mathrm{ml}$ for groups $1,2,3$ and 4 respectively) and native CAT activity $(0.0401 \pm 0.0068$, $0.055 \pm 0.01,0.0389 \pm 0.0070,0.036 \pm 0.015 \mathrm{IU} / \mathrm{ml}$ for groups 1, 2, 3 and 4 respectively) were observed among groups. Quantification of antioxidant enzymes was performed after western blotting. We observed one protein band of $23 \mathrm{kDa}$ and 1 between 50 and $75 \mathrm{kDa}$ corresponding to GPXBI and GPXBS respectively (Vaisberg et al. 2005, Drevet 2006; Fig. 3A). GRD and SOD protein bands had 56 and $32 \mathrm{kDa}$ respectively (Fig. 3B and C). CAT protein band was observed at $64 \mathrm{kDa}$ (Fig. 3D). No differences in GPXBI immunodetection $(0.55 \pm 0.08,0.74 \pm 0.15,0.87 \pm 0.135,0.62 \pm 0.07$ for groups 1, 2, 3 and 4 respectively) and GPXBS immunodetection $(0.41 \pm 0.02, \quad 0.39 \pm 0.04, \quad 0.38 \pm 0.02$, $0.48 \pm 0.08$ for groups $1,2,3$ and 4 respectively) were observed. There was a trend $(P=0.06)$ that group 4 presented increased immunodetection (pixel/area) of GRD $(0.50 \pm 0.09$; Fig. 4A) when compared to groups 1 , 2 and 3 with lower induced lipid peroxidation susceptibility $(0.39 \pm 0.06,0.25 \pm 0.06$ and $0.26 \pm 0.05$ respectively; Fig. 4A). For immunodetection of native SOD, no differences were observed among groups $1,2,3$ and $4(2.49 \pm 0.41,2.40 \pm 0.68,2.84 \pm 0.57,1.38 \pm 0.62$ respectively). There was an increase in the native immunodetection of CAT (Fig. 4B) in the seminal plasma of groups $2(1.44 \pm 0.10), 3(1.42 \pm 0.12)$ and 4 $(1.31 \pm 0.12)$ respectively with average, high and highest susceptibility to induced lipid peroxidation when compared to group 1 (low susceptibility to peroxidation, $1.04 \pm 0.08$; Fig. 4B).

\section{Sperm evaluations, plasma membrane and acrosome integrity and mitochondrial membrane potential in ram sperm}

There was no effect of induced lipid peroxidation susceptibility on the native volume, motility, mass
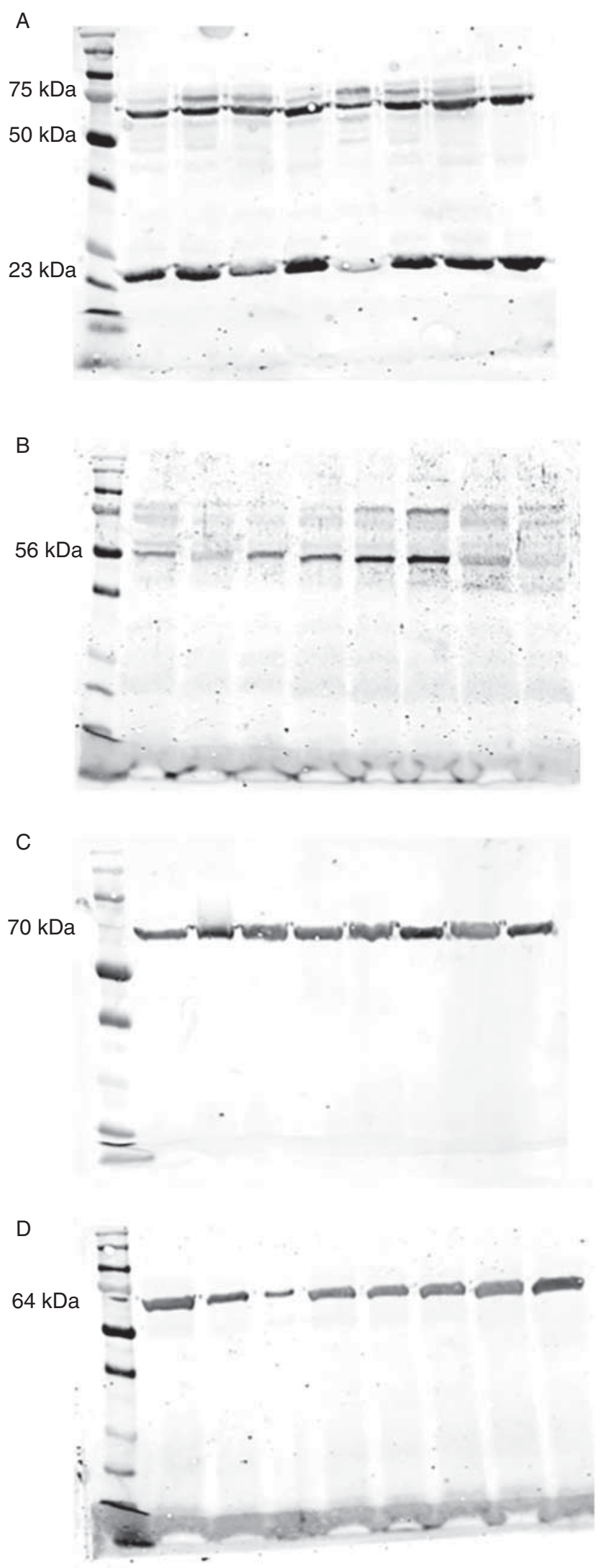

Figure 3 Immunoblotting detection of GPx (A), GRD (B), SOD (C) and CAT (D) in ram seminal plasma in different TBARS groups. 

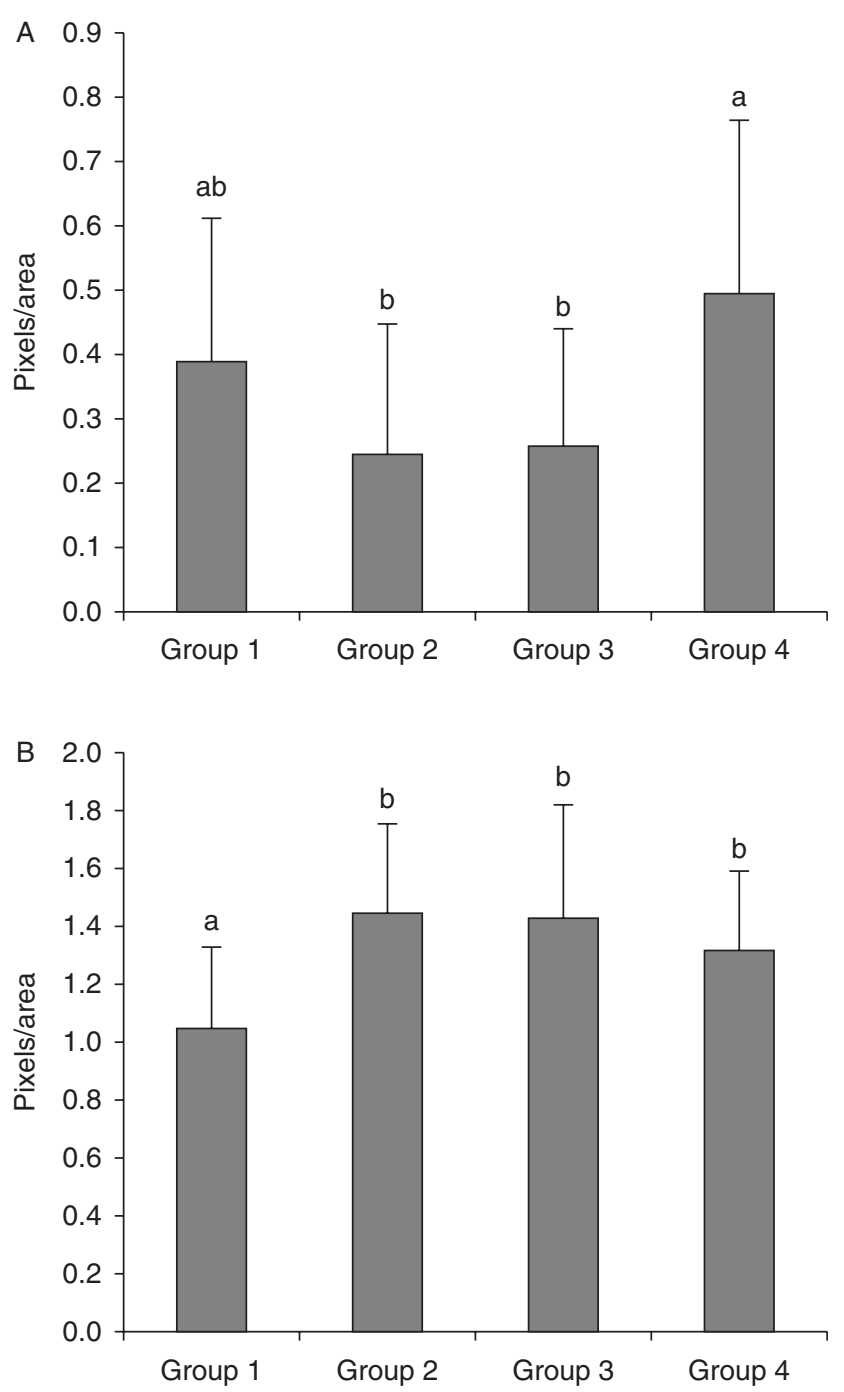

Figure 4 Immunodetection of GRD (A) and CAT (B) in seminal plasma in different TBARS groups (groups 1, 2, 3 and 4). The results are presented as means \pm s.D. Different superscript letters in each bar represent significant differences $(P<0.05)$.

motility and sperm concentration in groups (Table 1). Group 4 had a higher percentage of sperm with total defects $(14.70 \pm 2.51 \%)$ compared to groups $1(8.22 \pm$ $1.37 \%), 2(8.59 \pm 1.31 \%)$ and group $3(10.851 \pm 1.53 \%)$ and an increase in the percentage of major defects, $11.05 \pm 2.29 \%$ compared to groups 1, 2 and 3 (4.16 \pm 0 $90 \%, 4.203 \pm 6 \%, 0.59 \pm 1.16 \%$ respectively) (Fig. 5). No clear effect of lipid peroxidation status following induction could be observed on the percentages of native DMDA, IMIA, IMDA and DMIA sperm (Table 1). Groups 2 and 3 showed a reduction in the percentage of native cells with LMP $(20.02 \pm 1.71 \%, 19.99 \pm 1.97 \%$ respectively) when compared to groups 1 (26.55 \pm $2.55 \%)$ and $4(25.05 \pm 2.6 \%)$. There was no effect of induced lipid peroxidation susceptibility on high and MMP (Table 1).

\section{Sperm protamination and PRM1, TNP1 and TNP2 gene expression}

No effect of induced lipid peroxidation susceptibility on native protamine deficiency (CMA3 fluorochrome) was observed in sperm cells from all four groups (Table 1). However, differences were found in the native gene expression of PRM1 in groups. Group 4 (35.76 \pm 4.54$)$ presented an increase in the native number of PRM1 mRNA copies (Fig. 6) compared to groups 1 (20.23 \pm $3.98), 2(27.02 \pm 5.14)$ and $3(18.23 \pm 3.99)$, while no differences in native gene expression of TNP1 (5.96 \pm $1.17,4.12 \pm 0.58,4.67 \pm 0.77$ and $6.63 \pm 0.85$ respectively to groups $1,2,3$ and 4$)$ and TNP2 $(0.35 \pm 0.05$, $0.35 \pm 0.004,0.45 \pm 0.07$ and $0.46 \pm 0.04$ respectively to groups 1, 2, 3 and 4) were observed.

\section{Sperm DNA fragmentation}

Group 4 exhibited the highest percentage of native positive cells stained with acridine orange $(3.55 \pm$ $0.95 \%)$ vs groups $1(1.94 \pm 0.71 \%), 2(1.38 \pm 0.38 \%)$ and $3(1.98 \pm 0.60 \%)($ Fig. $7 \mathrm{~A})$, indicating higher DNA fragmentation. Comet assay revealed an increase of native sperm with Grade III of DNA fragmentation in group $4(6.47 \pm 3.24 \%)$ when compared to other groups (Fig. 7B). There were no differences in other degrees of DNA fragmentation (Fig. 7B).

\section{Discussion}

In the present study, semen from 12 rams was ranked according to induced lipid peroxidation susceptibility. It is important to note that each animal had ejaculates allocated to all experimental groups. We observed that groups with increased susceptibility to lipid peroxidation showed higher activity of GPx and decreased activity of GRD. Furthermore, results of the western blot revealed an increase in CAT in these groups. However, no differences were found in sperm intracellular free radicals or seminal plasma lipid peroxidation among groups. Samples with increased susceptibility to lipid peroxidation also showed increased percentage of sperm showing morphological abnormalities, acrosome and membrane damage and DNA fragmentation. Despite the increase in PRM1 gene expression, no differences on native protamination deficiencies were observed in the groups showing higher susceptibility to induced lipid peroxidation.

The higher activity of GPx in groups with median, high and highest susceptibility to induced lipid peroxidation agrees with data obtained in previous studies that evaluated the activity of this enzyme in human (Alvarez et al. 1987) and ram semen (Marti et al. 2003). Marti et al. (2007) observed an increase in SOD activity, GRD, GPx and CAT outside the breeding season, indicating a high antioxidant activity when sperm quality is lower, 
Table 1 Mean \pm S.E.M and probability $(P)$ for different variables in different TBARS groups (groups 1, 2, 3 and 4).

\begin{tabular}{|c|c|c|c|c|c|}
\hline Variables & $P$ value & Group 1 & Group 2 & Group 3 & Group 4 \\
\hline Seminal volume (ml) & 0.06 & $1.02 \pm 0.04$ & $1.17 \pm 0.04$ & $1.10 \pm 0.053$ & $1.01 \pm 0.02$ \\
\hline Motility $(\%)$ & 0.16 & $73.88 \pm 1.71$ & $76.48 \pm 0.95$ & $71.85 \pm 1.33$ & $73.70 \pm 1.65$ \\
\hline Mass motility (1-5) & 0.34 & $3.53 \pm 0.13$ & $3.77 \pm 0.11$ & $3.42 \pm 0.14$ & $3.65 \pm 0.17$ \\
\hline Major defects (\%) & 0.001 & $4.16 \pm 0.90^{\mathrm{a}}$ & $4.20 \pm 0.59^{\mathrm{a}}$ & $6.00 \pm 1.16^{\mathrm{a}}$ & $11.05 \pm 2.29^{b}$ \\
\hline Minor defects (\%) & 0.72 & $4.05 \pm 0.81$ & $3.59 \pm 0.899$ & $4.85 \pm 1.018$ & $3.65 \pm 0.74$ \\
\hline Total defects $(\%)$ & 0.05 & $8.22 \pm 1.37^{\mathrm{a}}$ & $8.60 \pm 1.31^{\mathrm{a}}$ & $10.85 \pm 1.53^{\mathrm{ab}}$ & $14.70 \pm 2.51^{\mathrm{b}}$ \\
\hline Sperm concentration $\left(\times 10^{9} / \mathrm{ml}\right)$ & 0.13 & $4.47 \pm 0.24$ & $4.29 \pm 0.212$ & $3.94 \pm 0.293$ & $3.60 \pm 0.243$ \\
\hline CMA3 fluorochrome (\%) & 0.43 & $1.87 \pm 0.51$ & $5.25 \pm 2.82$ & $6.64 \pm 2.341$ & $4.54 \pm 1.52$ \\
\hline IMDA sperm (\%) & 0.99 & $2.39 \pm 0.47$ & $3.43 \pm 1.21$ & $2.76 \pm 0.73$ & $1.99 \pm 0.34$ \\
\hline DMDA sperm (\%) & 0.01 & $34.99 \pm 2.60^{\mathrm{a}}$ & $25.05 \pm 2.34^{b}$ & $28.14 \pm 2.36^{\mathrm{b}}$ & $30.96 \pm 1.69^{\mathrm{ab}}$ \\
\hline DMIA sperm $(\%)$ & 0.87 & $36.20 \pm 1.64$ & $34.43 \pm 2.35$ & $34.16 \pm 1.735$ & $34.94 \pm 1.44$ \\
\hline IMIA sperm (\%) & 0.01 & $26.40 \pm 1.99^{\mathrm{a}}$ & $37.08 \pm 2.82^{\mathrm{b}}$ & $34.94 \pm 2.75^{b}$ & $32.12 \pm 2.3^{\mathrm{ab}}$ \\
\hline HMP sperm (\%) & 0.88 & $39.79 \pm 3.97$ & $42.98 \pm 3.34$ & $39.27 \pm 3.400$ & $40.94 \pm 3.55$ \\
\hline LMP sperm (\%) & 0.09 & $26.55 \pm 2.55^{\mathrm{a}}$ & $20.02 \pm 1.71^{\mathrm{ab}}$ & $19.99 \pm 1.97^{b}$ & $25.05 \pm 2.6^{\mathrm{ab}}$ \\
\hline MMP sperm $(\%)$ & 0.28 & $34.66 \pm 3.16$ & $36.99 \pm 2.98$ & $40.75 \pm 2.71$ & $34.01 \pm 2.53$ \\
\hline Positive sperm for fluorescein DCF (\%) & 0.53 & $9.11 \pm 1.70$ & $9.09 \pm 1.95$ & $6.06 \pm 1.60$ & $9.58 \pm 2.27$ \\
\hline
\end{tabular}

IMIA, intact membrane and intact acrosome. IMDA, intact membrane and damaged acrosome; DMIA, damaged membrane and intact acrosome; DMDA, damaged membrane and damaged acrosome; HMP, high mitochondrial membrane potential; LMP, low mitochondrial membrane potential; MMP, medium mitochondrial membrane potential; DCF, fluorescent probe dichlorofluorescein. Different superscript letters in each bar represent significant differences $(P<0.05)$.

which might keep the reproductive potential when conditions were less than ideal. Furthermore, using immunodetection, we observed an increase in CAT protein expression in groups with an increased susceptibility to lipid peroxidation (groups 2, 3 and 4) when compared to more resistant animals (group 1). Leahy et al. (2010) found that supplementation with CAT increased the resistance of lipid peroxidation prone cells against OS. CAT and GPx are the two main $\mathrm{H}_{2} \mathrm{O}_{2}$ scavenging systems in vivo (Halliwell \& Gutteridge 1999). CAT is responsible for the removal of high fluxes of $\mathrm{H}_{2} \mathrm{O}_{2}$ by means of peroxisomes, whereas GPx, a more complex system, deals with lower 'physiological' levels of $\mathrm{H}_{2} \mathrm{O}_{2}$ generation (Halliwell \& Gutteridge 1999). Despite the similar activity (i.e. $\mathrm{H}_{2} \mathrm{O}_{2}$ removal), these enzymes work in cooperation (Baud et al. 2004); both enzymes are able to deal with a wide range of $\mathrm{H}_{2} \mathrm{O}_{2}$ concentrations (Halliwell \& Gutteridge 1999). When facing low concentrations of $\mathrm{H}_{2} \mathrm{O}_{2}, \mathrm{GPx}$, enzyme with higher affinity for this ROS, acts as a primary scavenging system. On the other hand, CAT is responsible for antioxidant protection when a biological system is submitted to higher concentrations of $\mathrm{H}_{2} \mathrm{O}_{2}$ (Baud et al. 2004). In fact, an important function of GPx is to maintain the $\mathrm{H}_{2} \mathrm{O}_{2}$ levels below those in which CAT is required.

Although an increase in GPx enzyme activity was observed, no increase in this enzyme levels was observed in groups with increased susceptibility to lipid peroxidation. The high lipid peroxidation status stimulate the activation of GPx and the consequent catalysis of hydrogen peroxide (Alvarez \& Storey 1989, revised by Turner \& Lysiak 2008, Paul et al. 2009), which justifies the increased enzyme activity of GPx in seminal plasma found in this work. This study found decreased levels and enzymatic activity of GRD enzyme in groups with an increased susceptibility to lipid peroxidation. This could be explained by the catalytic cycle of glutathione and by the antioxidant action of GPx. GPx remove $\mathrm{H}_{2} \mathrm{O}_{2}$ by coupling its reduction to $\mathrm{H}_{2} \mathrm{O}$ with oxidation of reduced glutathione, $\mathrm{GSH}$, a thiolcontaining tripeptide, producing the oxidized glutathione (GSSG). The GPx enzymes are widely distributed in animal tissues and are mostly specific for GSH, as a hydrogen donor (Storey et al. 1998). The conversion of GSSG back to GSH is achieved by GRD. Aiming to maintain the protective activity of glutathione, the GSH needs to be regenerated via catalytic cycle. In this situation, GPx catalyzes the oxidation of GSH to GSSG, and GRD is responsible for the regeneration of GSH from GSSG in the presence of NADPH. Thus, the reduction of the enzymatic activity of GRD found in the present study, for samples showing higher susceptibility to lipid peroxidation, may indicate a greater consumption of this enzyme in order to increase the amount of GSH from

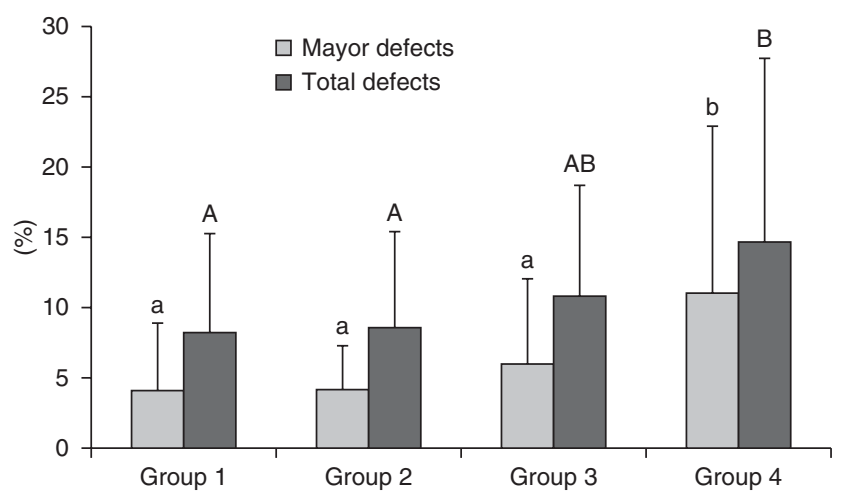

Figure 5 Sperm mayor and total defects in different TBARS groups (groups 1, 2, 3 and 4). The results are presented as means \pm s.D. Different superscript letters in each bar represent significant differences $(P<0.05)$. 


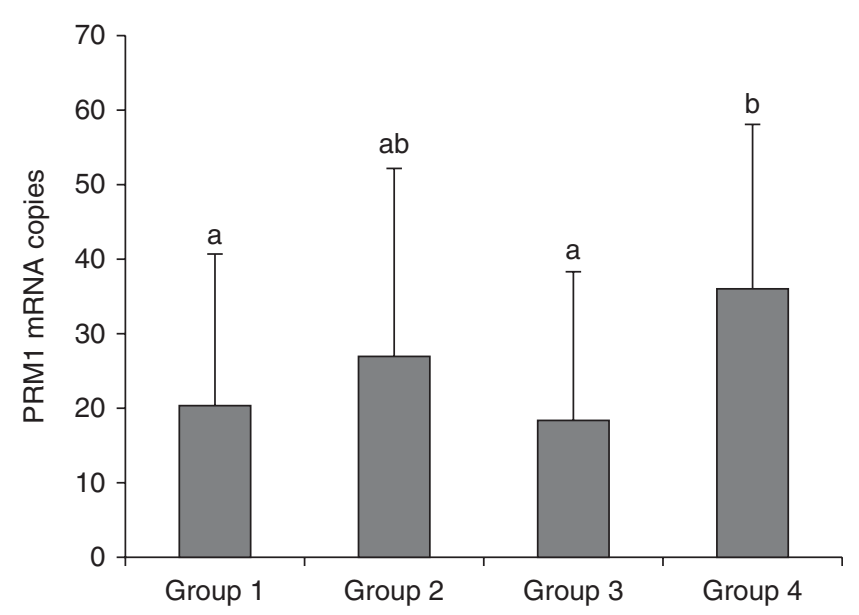

Figure 6 PRM1 mRNA copies in different TBARS groups (groups 1, 2, 3 and 4 ). The results are presented as means \pm s.D. Different superscript letters in each bar represent significant differences $(P<0.05)$.

GSSG catalysis and thus do the feedback for the catalytic cycle of the glutathione increasing the antioxidant activity of GPx.

The increased enzyme activity of GPx not accompanied by an increase in protein expression could indicate that this enzyme would be bioavailable and would be activated in case of necessity, especially in animals showing higher susceptibility to OS. In fact, a post-translational mechanism of protein activation would be more efficient and faster than the synthesis of new antioxidant enzymes, dependent of gene activation, transcription and translation (revised by Rhee et al. 2005). Similar results of discrepancies between enzyme expression and activity were found previously in the brain of mice during the development from fetal life to adulthood (Khan \& Black 2003) and in heart tissues subjected to antioxidant deficiency (Li \& Singal 2000). According to the authors, the first line of defense against OS would be highly dependent of post-translational regulation. Other mechanisms that control protein activity might be involved, such as the release of enzymes in compartmentalized areas of cell regulation by activators and inhibitors and covalent modulation changes in the cellular microenvironment (Jarrouge et al. 1997). Further studies are necessary to understand the mechanism of expression and activation of these antioxidant enzymes.

High levels of ROS in spermatozoa had been associated with decreased motility (Peris et al. 2007, Agarwal et al. 2014) and with peroxidation of unsaturated fatty acids present in the plasma membrane (Gomez et al. 1998). Morphological changes and sperm damage were observed in conditions of OS (e.g. teratospermia, varicocele and heat stress), as the incidence of sperm abnormalities and damages to the membrane, acrosome and DNA can be directly associated with the overproduction of ROS in semen
(Fleming et al. 2004, Nichi et al. 2006, Blumer et al. 2008, Blumer et al. 2011, Agarwal et al. 2014). In this study, we observed an increase in the percentage of total defects, mainly due to higher percentages of major defects in groups highly susceptible to the lipid peroxidation. Similarly, we found in these groups, a higher percentage of injuries to sperm acrosome and plasma membrane. Such damages occurred despite the absence of OS per se as observed on seminal plasma lipid peroxidation and intracellular free radicals. These results suggest that even in situations in which sperm OS is not evident as those observed in the present study, OS is directly or indirectly related to sperm abnormalities, membrane and acrosome damages, DNA fragmentation, probably due the increased susceptibility of sperm to occasional disruptions of such homeostasis.

Sperm mitochondria are involved in ATP production by oxidative phosphorylation. Some studies indicate a clear relationship between ROS and mitochondria, which are the main sources of ROS (Aitken et al. 1989, Argawal et al. 2008). In situations where there is an increase of ROS, mitochondria are affected (Murphy 2009). Similarly, alterations in mitochondria trigger the release of pro-oxidative factors, further intensifying the
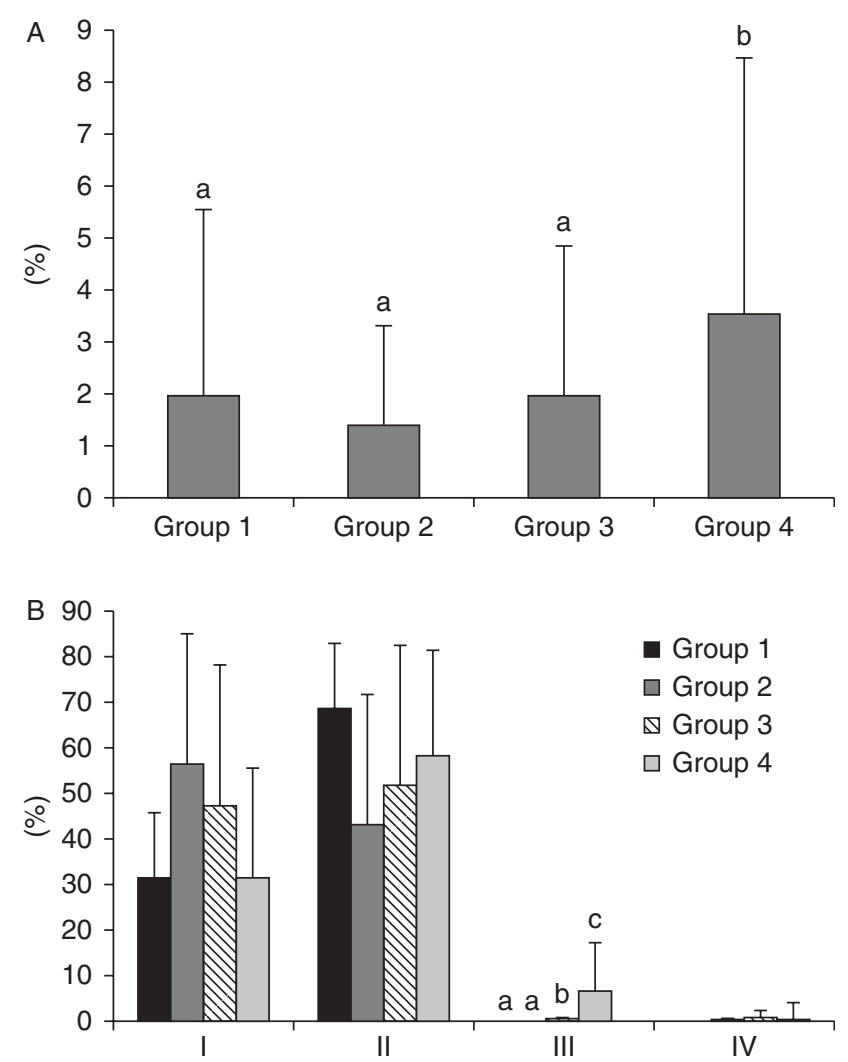

Figure 7 (A) Sperm fragmentation in different TBARS groups (groups 1, 2, 3 and 4). (B) Comet assay in different TBARS groups (groups 1, 2, 3 and 4) for different levels of chromatin fragmentation (levels: I, II, III and IV). The results are presented as means \pm s.D. Different superscript letters in each bar represent significant differences $(P<0.05)$. 
oxidative chain reaction (Murphy 2009). Ferramosca et al. (2013) reported a decrease in mitochondrial activity in patients who had high seminal levels of ROS. OS negatively affects mitochondrial activity by a decoupling mechanism between the electron carriers and ATP synthesis (Blumer et al. 2008). In this study, it was verified that groups with higher susceptibility to lipid peroxidation had lower percentage of sperm with LMP, accompanied by a non-significant increase in the percentage of sperm with intermediate potential. In agreement, studies in humans have found that cells with intermediate mitochondrial activity would be more accurate indicators of problems in the relationship between ROS and mitochondria than cells with high or low activity (Blumer et al. 2008, 2011). The partial mitochondrial activity would indicate cells that are currently releasing pro-oxidative factors, with potential to damage not only the host cell but also the surrounding cells, leading to an oxidative chain reaction (Blumer et al. 2011).

OS is the main cause of damage to the sperm chromatin (Sakkas \& Alvarez 2010). Sperm DNA integrity is essential for embryonic development (Fatehi et al. 2006), and for this reason, chromatin damage has been associated with infertility, particularly in idiopathic cases (Sharma \& Agarwall 1996). In this study, it can be seen that ram sperm with a high susceptibility to lipid peroxidation showed high susceptibility to chromatin damage. This result corroborates the results reported by Simões et al. (2013), in which samples of frozen, cattle semen, that had low susceptibility to lipid peroxidation, presented little susceptibility to chromatin damage. These authors also found that embryos produced using these samples of high susceptibility to lipid peroxidation showed more DNA damage, indicating the importance of sperm DNA integrity for the healthy embryo development.

Many researchers have reported the presence of high amounts of mRNA of PRM1 sperm in cattle (Feugang et al. 2010). This fact is not surprising, as the PRM1 is the main protein responsible for compaction of spermatic DNA, and remaining quantities of $\mathrm{mRNA}$ from spermatogenesis can still be found (Gilbert et al. 2007). Lambard et al. (2004) found higher amounts of mRNA PRM1 in sperm fractions with low motility in humans. However, Feugang et al. (2010) showed that sperm of high- and low-fertility bulls have similar expression of PRM1.

In this experiment, we observed an increase in the number of $P R M 1$ mRNA copies in sperm groups with increased susceptibility to lipid peroxidation. One of the reasons for these findings could be that the sperm, on the way to the female genital tract, has low transcriptional activity, which is transient, only trying to replace some protamines that may be defective (Feugang et al. 2010). In the group with the highest susceptibility to lipid peroxidation, an increased production of ROS during spermatogenesis could compromise gene transcription and thus increase the production of defective protamines (Feugang et al. 2010). Therefore, this increases the activity of sperm PRM1, attempting to replace these defective proteins (Feugang et al. 2010) in order to protect the DNA.

In summary, ram sperm susceptibility to lipid peroxidation may be involved in the impairment on sperm quality (i.e. acrosome and membrane damages, morphological abnormalities and mitochondrial lesions). We may also suggest that OS is a major cause of chromatin damage in this species. In an attempt to counter-attack these increased susceptibility to OS, antioxidant enzymes, especially CAT and GPx, are synthesized or activated aiming to maintain oxidative homeostasis. In addition, to avoid damages to sperm chromatin, there is an increase on transcriptional activity of PRM1.

\section{Supplementary data}

This is linked to the online version of the paper at http://dx.doi. org/10.1530/REP-15-0403.

\section{Declaration of interest}

The authors declare that there is no conflict of interest that could be perceived as prejudicing the impartiality of the research reported.

\section{Funding}

This work was supported by the Fundação de Amparo à Pesquisa do Estado de São Paulo (FAPESP) grant 2007/58487-1, grant 2011/11231-8 and grant 2013/05025-1 and the Conselho Nacional de Desenvolvimento Científico e Tecnológico (CNPq) grant 81700/11-0.

\section{Author contribution statement}

T R S Hamilton, M E Oz D' Assumpção, M Nichi and M D Goissis designed the experimental study; T R S Hamilton, L S Castro, P M Assis, J C Delgado, A F P Siqueira and C M Mendes managed the animals and analyzed sperm. T R S Hamilton performed gene expression, enzymatic activities, western blot and statistical analyses. T Muiño-Blanco and J Á Cebrián-Pérez performed and assisted with enzymatic activities and western blot analyses. T R S Hamilton, M Nichi, M D Goissis and J A Visintin drafted the manuscript, whereas M E Ortiz D'Ávila Assumpção provided financial support, completed critical revision and approval of the article.

\section{References}

Agarwal A, Saleh RA \& Bedaiwym A 2003 Role of reactive oxygen species in the pathophysiology of human reproduction. Fertility and Sterility $\mathbf{7 9}$ 829-843. (doi:10.1016/S0015-0282(02)04948-8)

Agarwal AL, Makker K \& Sharma R 2008 Clinical relevance of oxidative stress in male factor infertility: an update. American Journal of Reproductive Immunology 59 2-11. (doi:10.1111/j.1600-0897.2007.00559.x) 
Agarwal AL, Tvrda E \& Sharma R 2014 Relationship amongst teratozoospermia, seminal oxidative stress and male infertility. Reproductive Biology and Endocrinology 12 1-8. (doi:10.1186/1477-7827-12-1)

Ahmadi A \& Ng SC 1999 Fertilizing ability of DNA-damaged spermatozoa. Journal of Experimental Zoology 284 696-704. (doi:10.1002/(SICI)1097010X(19991101)284:6<696::AID-JEZ11>3.0.CO;2-E)

Aitken RJ \& Barker MA 2002 Reactive oxygen species generation by human spermatozoa: a continuing enigma. International Journal of Andrology 25 191-194. (doi:10.1046/j.1365-2605.2002.03521.x)

Aitken RJ \& Clarkson JS 1987 Cellular basis of defective sperm function and its association with the genesis of reactive oxygen species by human spermatozoa. Journal of Reproduction and Fertility 81 459-469. (doi:10. 1530/jrf.0.0810459)

Aitken RJ \& Krausz C 2001 Oxidative stress, DNA damage and the $Y$ chromosome. Reproduction 122 497-506. (doi:10.1530/rep.0.1220497)

Aitken RJ, Clarkson JS \& Fishel S 1989 Generation of reactive oxygen species, lipid peroxidation, and human sperm function. Biology of Reproduction 41 183-197. (doi:10.1095/biolreprod41.1.183)

Aitken RJ, Harkiss D \& Buchingham D 1993 Relationship between ironcatalysed lipid peroxidation potential and human sperm function. Journal of Reproduction and Fertility 98 257-265. (doi:10.1530/jrf.0. 0980257)

Alvarez JG \& Storey B 1989 Role of glutathione peroxidase in protecting mammalian spermatozoa from loss of motility caused by spontaneous lipid peroxidation. Gamete Research 23 79-90. (doi:10.1002/mrd. 1120230108)

Alvarez JG \& Storey BT 1992 Evidence for increased lipid peroxidative damage and loss of superoxide dismutase activity as a mode of sub lethal cryodamage to human sperm during cryopreservation. Journal of Andrology 13 232-241. (doi:10.1002/j.1939-4640.1992.tb00306.x)

Alvarez JG, Touchstone JC, Blasco L \& Storey B 1987 Spontaneous lipid peroxidation and production of hydrogen peroxide and superoxide in human spermatozoa, superoxide dismutase as major enzyme protectant against oxygen toxicity. Journal of Andrology 8 338-348. (doi:10.1002/j. 1939-4640.1987.tb00973.x)

Bansal AK \& Bilaspuri GS 2008 Effect of ferrous sulphate and ascorbic acid on motility, viability and lipid peroxidation of crossbred cattle bull spermatozoa. Animal 2 100-104. (doi:10.1017/S1751731107000961)

Baud O, Greene AE, Li J, Wang H, Volpe JJ \& Rosenberg PA 2004 Glutathione peroxidase-catalase cooperativity is required for resistance to hydrogen peroxide by mature rat oligodendrocytes. Journal of Neuroscience 24 1531-1540. (doi:10.1523/JNEUROSCI.3989-03.2004)

Blom E 1973 The ultrastructure of some characteristics sperm defects and a proposal for a new classification of the bull spermiogram. Nordisk Veterinaermedicin 25 383-391.

Blumer CG, Fariello RM, Restelli AE, Spaine DM, Bertolla RP \& Cedenho AP 2008 Sperm nuclear DNA fragmentation and mitochondrial activity in men with varicocele. Fertility and Sterility 90 1716-1722. (doi:10.1016/j.fertnstert.2007.09.007)

Blumer CG, Restelli AE, Del Giudice PT, Soler TB, Fraietta R, Nichi M, Bertolla RP \& Cedenho AP 2011 Effect of varicocele on sperm function and semen oxidative stress. BJU International 109 259-265. (doi:10. 1111/j.1464-410X.2011.10240.x)

Bradford M 1976 A rapid and sensitive method for the quantification of microgram quantities of protein utilizing the principle of protein dye binding. Analytical Biochemistry 72 248-254. (doi:10.1016/00032697(76)90527-3)

Donnely ET, OConnell M, Mcclure N \& Lewis SE 2000 Differences in nuclear DNA fragmentation and mitochondrial integrity of semen and prepared human spermatozoa. Human Reproduction 15 1552-1561. (doi:10.1093/humrep/15.7.1552)

Drevet JR 2006 The antioxidant glutathione peroxidase family and spermatozoa: a complex story. Molecular and Cellular Endocrinology 250 70-79. (doi:10.1016/j.mce.2005.12.027)

Evenson DP \& Wixon R 2006 Clinical aspects of sperm DNA fragmentation detection and male infertility. Theriogenology 65 979-991. (doi:10. 1016/j.theriogenology.2005.09.011)

Fatehi AN, Bevers MM, Schoevers E, Roelen BA, Colenbrander B \& Gadella BM 2006 DNA damage in bovine sperm does not block fertilization and early embryonic development but induces apoptosis after the first cleavages. Journal of Andrology 27 176-188. (doi:10.2164/ jandrol.04152)
Ferramosca A, Provenzano SP, Montagna DD, Coppola L \& Zara V 2013 Oxidative stress negatively affects human sperm mitochondrial respiration. Urology 82 78-83. (doi:10.1016/j.urology.2013.03.058)

Feugang JM, Rodrigez-Osorio N, Kaya A, Wang H, Page G, Ostermeier GC, Topper EK \& Memili E 2010 Transcriptome analysis of bull spermatozoa: implications for male fertility. Reproductive Biomedicine Online 21 312-324. (doi:10.1016/j.rbmo.2010.06.022)

Fleming JS, Fu Yu, Macdonald RM, Neyers SA, Montgomery GW, Smith JF \& Nicholson H 2004 Effects of scrotal heating on sperm surface protein $\mathrm{PH}-20$ expression in sheep. Molecular Reproduction and Development 68 103-114. (doi:10.1002/mrd.20049)

Gilbert I, Bissonnette N, Boissonneault G, Vallée M \& Robert CA 2007 A molecular analysis of the population of mRNA in bovine spermatozoa. Reproduction 133 1073-1086. (doi:10.1530/REP-06-0292)

Gomes A, Fernandes E \& Lima JL 2005 Fluorescence probes used for detection of reactive oxygen species. Journal of Biochemical and Biophysical Methods 65 45-80. (doi:10.1016/j.jbbm.2005.10.003)

Gomez E, Irvine DS \& Aitken RJ 1998 Evaluation of a spectrophotometric assay for the measurement of malondialdehyde and 4-hydroxyalkenals in human spermatozoa: relationships with semen quality and sperm function. International Journal of Andrology 21 81-94. (doi:10.1046/j. 1365-2605.1998.00106.x)

Halliwell B \& Gutteridge JMC 1999 Antioxidant defence enzymes: the glutathione peroxidase family. In: Free radicals in biology and medicine, 3th edn, pp 140-172. Oxford: Oxford University Press.

Halliwell B \& Gutteridge JMC 2007 Cellular responses to oxidative stress: adaptation, damage, repair, senescence and death. In Free Radicals in Biology and Medicine, 4th edn, pp 187-268. Oxford: Oxford University Press.

Hammadeh M, Hamad M, Montenarh M \& Fisher-Hammadeh C 2010 Protamine contents and P1/P2 ratio in human spermatozoa from smokers and non-smokers. Human Reproduction 25 2708-2720. (doi:10.1093/ humrep/deq226)

Holt W 2000 Fundamental aspects of sperm cryobiology: the importance of species and individual differences. Theriogenology 53 47-58. (doi:10. 1016/S0093-691X(99)00239-3)

Hossain MS, Johannisson A, Wallgren M, Nagy S, Siqueira AP \& RodriguezMartinez H 2011 Flow cytometry for the assessment of animal sperm integrity and functionality: state of the art. Asian Journal of Andrology $\mathbf{1 3}$ 406-419. (doi:10.1038/aja.2011.15)

Jarrouge MG, Domingos MF, Tundisi M \& Martin NF 1997 Regulação do Metabolismo. In Bioquímica Básica, 4th edn, pp 207-263. São Paulo: Luana Livraria e Editora LTDA.

Kankofer M, Kolm M, Aurich J \& Aurich C 2005 Activity of glutathione peroxidase, superoxide dismutase and catalase and lipid peroxidation intensity in stallion semen during storage at $58^{\circ} \mathrm{C}$. Theriogenology 63 1354-1365. (doi:10.1016/j.theriogenology.2004.07.005)

Khan JY \& Black SM 2003 Developmental changes in murine brain antioxidant enzymes. Pediatric Research 54 77-82. (doi:10.1203/01. PDR.0000065736.69214.20)

Kim S, Yu D \& Kim Y 2010 Apoptosis-like change, ROS, and DNA status in cryopreserved canine sperm recovered by glass wool filtration and Percoll gradient centrifugation techniques. Animal Reproduction Science 119 106-114. (doi:10.1016/j.anireprosci.2009.11.002)

Lambard S, Galeraud-Denis I, Martin G, Levy R, Chocat A \& Carreau S 2004 Analysis and significance of mRNA in human ejaculated sperm from normozoospermic donors: relationship to sperm motility and capacitation. Molecular Human Repoduction 10 535-541. (doi:10. 1093/molehr/gah064)

Leahy T, Celi P, Bathgate R, Evans G, Maxwell WM \& Marti JI 2010 Flow-sorted ram spermatozoa are highly susceptible to hydrogen peroxide damage but are protected by seminal plasma and catalase. Reproduction, Fertility, and Development 22 1131-1140. (doi:10.1071/ RD09286)

Lenzi A, Gandini L, Picardo M, Tramer F, Sandri G \& Panfili E 2000 Lipoperoxidation damage of spermatozoa polyunsatured fatty acids (PUFA): scavenger mechanisms and possible scavenger therapies. Frontiers in Bioscience 5 1-5. (doi:10.2741/Lenzi)

Li T \& Singal PK 2000 Adriamycin-induced early changes in myocardial antioxidant enzymes and their modulation by probucol. Circulation 102 2105-2110. (doi:10.1161/01.CIR.102.17.2105)

Mahfouz R, Rakesh S, Lackner J, Aziz N \& Agarwal A 2009 Evaluation of chemiluminescence and flow cytometry as tools in assessing 
production of hydrogen peroxide and superoxide anion in human spermatozoa. Fertility and Sterility 92 819-827. (doi:10.1016/j.fertnstert. 2008.05.087)

Makker K, Agarwal A \& Sharma R 2009 Oxidative stress \& male infertility. Indian Journal of Medical Research 129 357-367.

Marti J, Marti E, Cebrián-Pérez J \& Muiño-Blanco MT 2003 Survival rate and antioxidant enzyme activity of ram spermatozoa after dilution with different extenders or selection by a dextran swim-up procedure. Theriogenology 60 1025-1037. (doi:10.1016/S0093691X(03)00105-5)

Marti E, Mara L, Marti JI, Muiño-Blanco MT \& Cebrián-Pérez JA 2007 Seasonal variations in antioxidant enzyme activity in ram seminal plasma. Theriogenology 67 1446-1454. (doi:10.1016/j.theriogenology. 2007.03.002)

Mojica-Villegas MA, Izquierdo-Vega JA, Charmorro-Cevallos G \& Sánchez-Gutiérrez M 2014 Protective effect of resveratrol on biomarkers of oxidative stress induced by iron/ascorbate in mouse spermatozoa. Nutrients 6 489-503. (doi:10.3390/nu6020489)

Murphy MP 2009 How mitochondria produce reactive oxygen species? Biochemical Journal I417 1-13. (doi:10.1042/BJ20081386)

Nichi M, Bols PE, Zuge RM, Barnabe VH, Goovaerts IG, Barnabe RC \& Cortada CN 2006 Seasonal variation in semen quality in Bos indicus and Bos taurus bulls raised under tropical conditions. Theriogenology $\mathbf{6 6}$ 822-828. (doi:10.1016/j.theriogenology.2006.01.056)

Ohkawa H, Ohishi N \& Yagi K 1979 Assay for lipid peroxides in animal tissues by thiobarbituric acid reaction. Analytical Biochemistry 95 351-358. (doi:10.1016/0003-2697(79)90738-3)

Parks JE \& Hammerstedt RH 1985 Developmental changes occuring in the lipids of ram epididymal spermatozoa plasma membrane. Biology of Reproduction 32 653-668. (doi:10.1095/biolreprod32.3.653)

Paul C, Teng S \& Saunders PT 2009 A single, mild, transient scrotal heat stress causes hypoxia and oxidative stress in mouse testes, which induces germ cell death. Biology of Reproduction 80 913-919. (doi:10.1095/ biolreprod.108.071779)

Peris SI, Bilodeau JF, Dufour M \& Bailey JL 2007 Impact of cryopreservation and reactive oxygen species on DNA integrity, lipid peroxidation, and functional parameters in ram sperm. Molecular Reproduction Development 74 878-892. (doi:10.1002/mrd.20686)

Rhee SG, Yang K, Kang SW, Woo HA \& Chang T 2005 Controlled elimination of intracellular $\mathrm{H}_{2} \mathrm{O}_{2}$ : regulation of peroxiredoxin, catalase, and glutathione peroxidase via post-translational modification. Antioxidants \& Redox Signaling 7 619-626. (doi:10.1089/ars.2005.7.619)

Sakkas D \& Alvarez JG 2010 Sperm DNA fragmentation: mechanisms of origin, impact on reproductive outcome, and analysis. Fertility and Sterility 93 1027-1036. (doi:10.1016/j.fertnstert.2009.10.046)

Sharma RK \& Agarwal A 1996 Role of reactive oxygen species in male infertility. Urology 48 835-850. (doi:10.1016/S0090-4295(96) 00313-5)
Simões R, Feitosa WB, Mendes CM, Marques MG, Nicacio AC, Barros FRO, Visintin JA \& Assumpção MEOA 2009 Use of chromomycin A3 staining in bovine sperm cells for detection of protamine deficiency. Biotechnic \& Histochemistry 83 79-83. (doi:10.1080/10520290 902843595)

Simões R, Feitosa WB, Siqueira AFP, Nichi M, Paula-Lopes FF, Marques MG, Peres MA, Barnabe VH, Visintin JA \& Assumpção MEOA 2013 Influence of bovine sperm DNA fragmentation and oxidative stress on early embryo in vitro development outcome. Reproduction 146 433-441. (doi:10.1530/REP-13-0123)

Storey BT, Alvarez JG \& Thompson KA 1998 Human sperm glutathione reductase activity in situ reveals limitation in the glutathione antioxidant defense system due to supply of NADPH. Molecular Reproduction and Development 49 400-407. (doi:10.1002/(SICl)1098-2795(199804)49:4 $<400:$ :AID-MRD7> 3.0.CO;2-R)

Tamburrino L, Marchiani S, Montoya M, Marino FE, Natali I, Cambi M, Forti G, Baldi E \& Muratori M 2012 Mechanisms and clinical correlates of sperm DNA damage. Asian Journal of Andrology $\mathbf{1 4}$ 24-31. (doi:10.1038/aja.2011.59)

Tesarik J, Mendonza C \& Greco E 2002 Paternal affects acting during the first cell cycle of human preimplantation development after ICSK. Human Reproduction 17 184-189. (doi:10.1093/humrep/17.1.184)

Turner TT \& Lysiak J 2008 Oxidative stress: a common factor in testicular dysfuction. Journal of Andrology 29 488-498. (doi:10.2164/jandrol.108. 005132)

Vaisberg CN, Jelezarsky LV, Dishlianova B \& Chaushev TA 2005 Activity, substrate detection and immunolocalization of glutathione peroxidase (GPx) in bovine reproductive organs and semen. Theriogenology 64 416-428. (doi:10.1016/j.theriogenology.2004.12.009)

Virro MR, Larson-Cook KL \& Evenson DP 2004 Sperm chromatin structure assay (SCSA) parameters are related to fertilization, blastocyst development, and ongoing pregnancy in in vitro fertilization and intracytoplasmic sperm injection cycles. Fertility and Sterility $\mathbf{8 1}$ 1289-1295. (doi:10.1016/j.fertnstert.2003.09.063)

Watson P 1981 The roles of lipid and protein in the protection of ram spermatozoa at 5 degrees $\mathrm{C}$ by egg-yolk lipoprotein. Journal of Reproduction and Fertility 62 483-492. (doi:10.1530/jrf.0.0620483)

White I 1993 Lipid and calcium uptake of sperm in relation to cold shock and preservation: a review. Reproduction, Fertility, and Development $\mathbf{5}$ 639-658. (doi:10.1071/RD9930639)

Received 2 September 2015

First decision 29 September 2015

Revised manuscript received 18 December 2015

Accepted 25 January 2016 